\title{
Monosegment ALPPS for bilateral colorectal liver metastasis - One is enough
}

\author{
Klaus Steinbrück ${ }^{1,2}$, Reinaldo Fernandes ${ }^{1,2}$, Gustavo Stoduto ${ }^{2}$, and Thomas Auel ${ }^{2}$ \\ ${ }^{1}$ Equipe Multidisciplinar Hepatobiliar - EMHep, \\ ${ }^{2}$ Hepatobiliary Unit, Bonsucesso Federal Hospital, Health Ministry, Rio de Janeiro, Brazil
}

\begin{abstract}
Associated liver partition and portal vein ligation for staged hepatectomy - ALPPS - procedure emerged as an alternative to treat patients needing extensive hepatic resections, but with a small future liver remnant. Initially described using the left lateral segments as liver remnant, ALPPS has been adapted to leave as remainder only one segment. Describe a case of a patiente with bilobar colorectal liver metastasis submitted to segment 4-1 ALPPS. A 63-year-old man, previously submitted to transversostomy, due to a left colon stenosing adenocarcinoma, associated to bilobar liver metastasis, was referred for our evaluation, after receiving a FOLFOX based chemotherapy. Due to the large load of tumor within the liver, we opted to perform a segment 4-1 ALPPS, which was carried out with an interval of 21 days between first and second stages. The liver remnant increased from $250 \mathrm{cc}$ to $694 \mathrm{cc}(18 \%$ to $48 \%$ of standard liver volume). The patient was discharged 15 days after second stage surgery and was subjected to left colectomy after five months. He is disease-free ten months after liver surgery. Monosegment ALPPS is a challenging, but feasible procedure, that should be criteriously indicated in selected patients and performed by a hepatobiliary surgery team with experience in complex major hepatectomies. (Ann Hepatobiliary Pancreat Surg 2020;24:522-525)
\end{abstract}

Key Words: Liver; Surgery; Metastasis; Colorectal neoplasms; Surgical oncology

\section{INTRODUCTION}

Associated liver partition and portal vein ligation for staged hepatectomy (ALPPS) procedure emerged as an alternative treatment for patients with a large load of tumor within the liver and a small future liver remnant (FLR). ${ }^{1}$ Despite the initial critics and high morbi-mortality worldwide, ${ }^{1}$ ALPPS passed through the test of time, and is still been performed, but the indications are more restricted nowadays. ${ }^{2,3}$ Initially described using the left lateral segments as FLR, ${ }^{1}$ ALPPS has been adapted in selected cases, using only one segment as FLR. ${ }^{4-11}$ Herein, we describe a case of a patient with bilobar colorectal liver metastasis (CRLM) submitted to segment 4-1 ALPPS with liver-first approach.

\section{CASE}

A 63-year-old man (height: $169 \mathrm{~cm}$; weight $70 \mathrm{~kg}$; BMI 24.5) was referred for our evaluation seven months after being submitted to an urgent transversostomy, due to a left colon stenosing adenocarcinoma (previously confirmed by biopsy), causing intestinal obstruction. After surgery, the patient was staged and abdominal CT scan revealed multiple liver implants in almost all hepatic segments (Fig. 1). No extra hepatic implants were identified. CEA value at this time was $196 \mathrm{ng} / \mathrm{dl}$. He received six cycles of FOLFOX based chemotherapy and was restaged. CEA value dropped to $1.8 \mathrm{ng} / \mathrm{dl}$. A MRI scan showed that the liver tumors reduced in volume, yet left lateral section and right liver still compromised. The caudate lobe was free of disease and segment 4 had two peripheral lesions that could be cleared by edge resection (Fig. 1). Volume of segments $4+1$ was estimated at $250 \mathrm{cc}$, corresponding to

Received: June 13, 2020; Revised: July 10, 2020; Accepted: July 12, 2020

Corresponding author: Klaus Steinbrück

Hepatobiliary Unit, Bonsucesso Federal Hospital, Av. Londres 616, prédio 3/2 ${ }^{\circ}$ andar, Rio de Janeiro/RJ, CEP: 21041-030, Brazil Tel: +55-21-39779811, Fax: +55-21-39779811, E-mail: steinbruck@gmail.com

Copyright (C) 2020 by The Korean Association of Hepato-Biliary-Pancreatic Surgery

This is an Open Access article distributed under the terms of the Creative Commons Attribution Non-Commercial License (http://creativecommons.org/ licenses/by-nc/4.0) which permits unrestricted non-commercial use, distribution, and reproduction in any medium, provided the original work is properly cited. Annals of Hepato-Biliary-Pancreatic Surgery • pISSN: 2508-5778 • elSSN: 2508-5859 

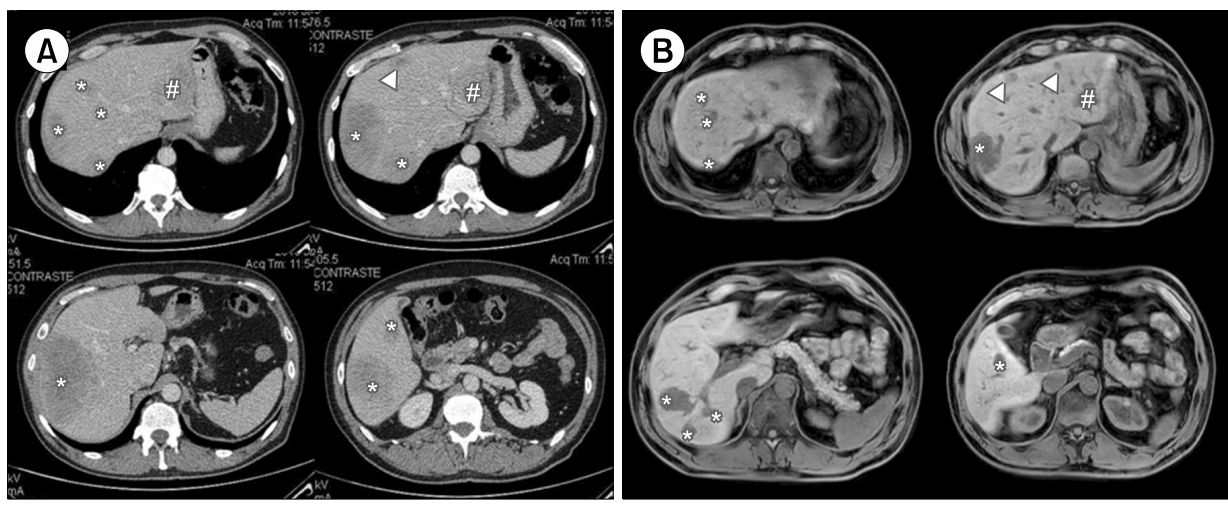

Fig. 1. (A) CT scan before chemotherapy; (B) MRI scan after chemotherapy; in both images, you can see lesions in the right liver $(*)$, in the left lateral section (\#) and in segment 4 (arrowhead).
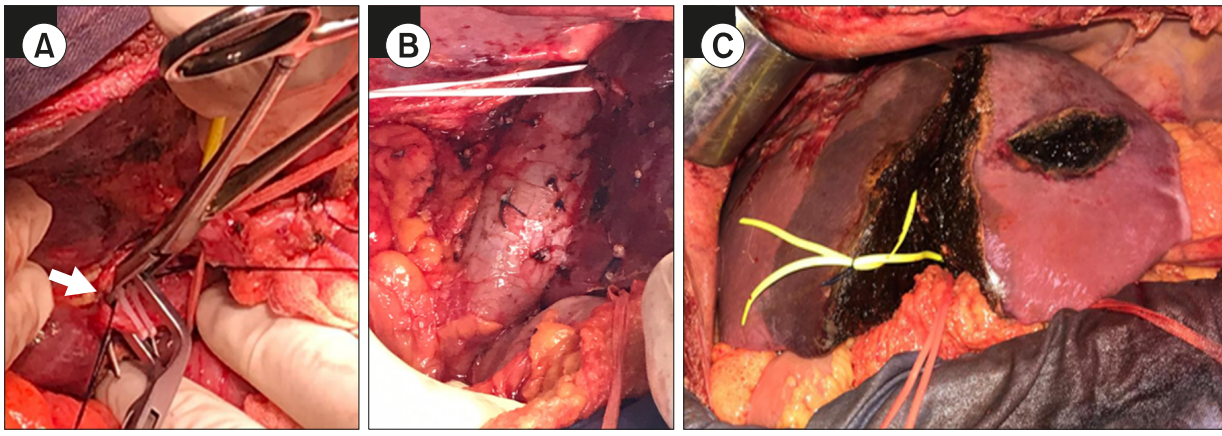

Fig. 2. (A) Right portal vein was ligated with hem-o-lok clips (arrow); (B) right hepatic vein encircled with white tape; (C) final aspect of the liver after $1^{\text {st }}$ stage surgery; right hilar plate encircled with yellow tape; right hepatic artery (not seen) encircled with red tape.

$18 \%$ of standard liver volume (SLV) and $0.36 \mathrm{FLR} / \mathrm{BW}$ ratio. After multidisciplinary team discussion and based on our recent experience with a similar case, we opted to perform a liver-first approach with a segment 4-1 ALPPS.

Stage 1 surgery was carried out under open technique with a J-shape incision. First, we performed the left lateral sectionectomy with intra-hepatic ligation and division of vascular pedicles with automatic stapler, associated to segment 4 clearing of lesions. Then, we proceeded with parenchyma transection using hanging maneuver, ultrasonic dissector/aspirator and bipolar sealant device. Hepatic pedicle was taped, but Pringle maneuver was not performed during hepatotomy. The right portal vein was ligated with hem-o-lok clips and divided. Vessel loops were placed around the right hilar plate, right hepatic artery (RHA) and the right hepatic vein (RHV) (Fig. 2). Cholecystectomy was performed and saline and air was injected through the cystic duct to look for bile leakage points. Drains were positioned in the right subphrenic space and in the transection space. The procedure lasted 350 minutes and the patient received no blood transfusion. He stayed in ICU for three days. On the 6th post-operative day (POD) patient presented cough, fever, elevation of white blood cells and $\mathrm{C}$ reactive protein. CT scan re- vealed bilateral pneumonia and Piperacilin with Tazobactam was initiated. Owing to the lung infection and antibiotic treatment, the 2 nd stage was carried out only 21 days after de first surgery. CT scan from the 18th POD showed an expressive growth of the FLR to $694 \mathrm{cc}$ (an increase of $277 \%$ ), corresponding to $48 \%$ of SLV and 0.98 FLR/BW ratio (Fig. 3). The 2nd stage was technically difficult due to inflammation process involving the right hilar plate, which was ligated and divided with automatic stapler with extremely care to avoid bleeding. RHA and RHV were ligated with polypropylene suture and divided. Stage 2 lasted 270 minutes and patient received one blood unit transfusion. He stayed for five days in ICU after 2nd surgery and developed a grade A liver disfunction after operation. He also developed a large right-sided pleural effusion, which was drained by thoracocentesis, and a low debit biliary fistula, treated conservatively. The patient was discharged on the 15th POD, after 2nd stage surgery, completing 36 days of hospital stay. He was subjected to left colectomy after five months and is disease-free ten months after liver surgery. 

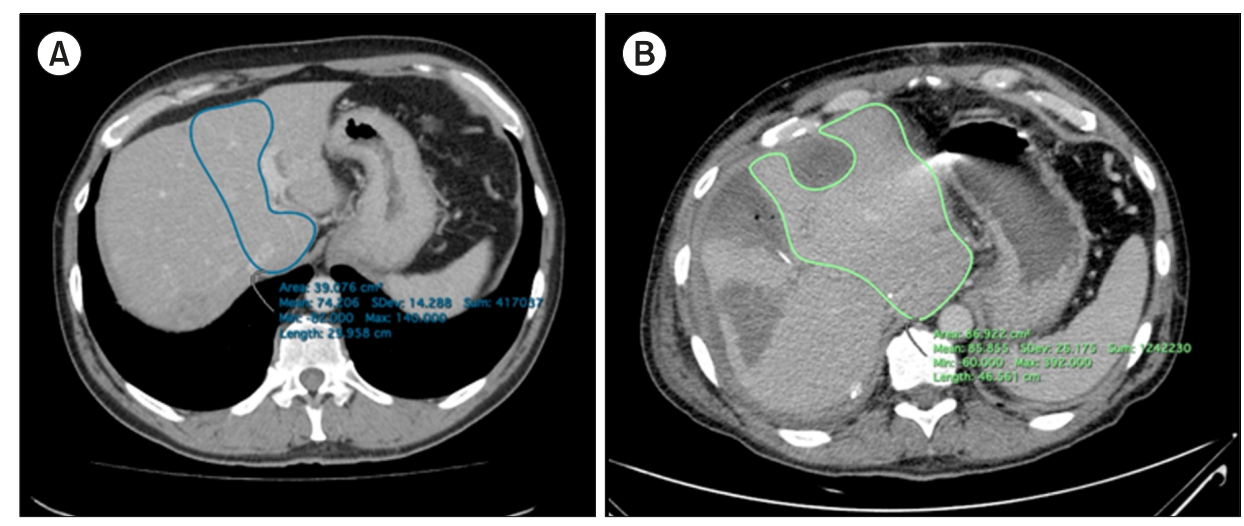

Fig. 3. (A) Segment 4 of the liver before ALPPS; (B) segment 4 of the liver after $1^{\text {st }}$ stage surgery, showing expressive hypertrophy.

\section{DISCUSSION}

Since the initial series published by Schnitzbauer et al., ${ }^{1}$ ALPPS approach has been exhaustively discussed and passed through many "probations". Even though, there are reports of ALPPS in patients with cholangiocarcinoma ${ }^{12}$ and hepatocellular carcinoma, ${ }^{13}$ better outcomes have been achieved for cases of bilobar CRLM, especially in patients under 60 years of age. ${ }^{2}$ Recent papers emphasize the role of ALPPS as a salvage procedure for patients that fail to achieve adequate hypertrophy of the FLR with percutaneous portal embolization. ${ }^{3}$ Originally performed using the left lateral section as FLR, ALPPS has been modified to use only one segment as FLR. After reading the paper by de Santibañes ${ }^{4}$ describing the segment 4-1 ALPPS, we performed our first monosegment ALPPS in 2015 with excellent result. ${ }^{5}$ So far, we could find 19 reports of monosegment ALPPS in literature, ${ }^{4-11}$ most of them using segment 4 as FLR, associated or not with segment 1. Even though, the majority of cases correspond to adult patients with CRLM, as our case described here, we found two interesting reports of segment 6 ALPPS, one in a 3-yearold child with hepatoblastoma, ${ }^{10}$ and other in an adult with intra-hepatic cholangiocarcinoma involving the three hepatic veins. ${ }^{8}$

Different from our first case, witch patient had bulky lesions involving the left lateral section and right liver, the patient described here had smaller lesions spread out through the liver parenchyma, involving the pedicles from segments 2 and 3 and all segments from right liver, similarly to the 12 cases reported previously in the review paper by Schadde et al. ${ }^{11}$ After 1st stage, we could observe an expressive hypertrophy of the FLR of $277 \%$, which is the higher value among all cases of monosegment ALPPS, that we found in literature. Even though, we needed to wait for 21 days to perform the 2 nd stage, due to the pneumonia, this great hypertrophy was already been noticed on the 6th POD, during the CT scan of the thorax. Like our first case, this patient experienced a grade A liver dysfunction (according to ISGLS $^{14}$ ) after stage 2. This complication was also observed in other cases described before, with no further implications. We believe that outflow congestion may play a role in this disfunction. The patient also developed a pleural effusion, drained by thoracocentesis, corresponding to Clavien-Dindo grade IIIA complication. Regarding the disease-free survival, this patient had no recurrence after 10 months and is still under surveillance. Our first patient had recurrence of disease in the right adrenal and lung, which were resected 36 and 39 months after surgery, respectively. She is still alive, 57 months after ALPPS. In the cases found in literature, considering patients with CRLM, the disease-free survival and overall survival for monosegment ALPPS are 14.6 and 20.1 months, respectively. Those short time results could be explained by the aggressiveness of disease affecting those patients and that is why they were submitted to such complex procedure. On the other hand, without surgery, those results would have been probably worse.

\section{CONCLUSION}

The ALPPS approach has become a reality and an important tool in the arsenal of the hepatobiliary surgeon. Leave only one hepatic segment, as in monosegment ALPPS, is a challenging, but feasible and safe procedure, that should be criteriously indicated as part of the onco- 
logical treatment of selected patients. It should be performed by a hepatobiliary team with experience in complex major hepatectomies, preferably for patients with CRLM.

\section{CONFLICT OF INTEREST}

There are no conflicts of interest.

\section{ORCID}

Klaus Steinbrück: https://orcid.org/0000-0002-3601-7272

Reinaldo Fernandes:

https://orcid.org/0000-0001-8759-2552

Gustavo Stoduto: https://orcid.org/0000-0001-8806-8584

Thomas Auel: https://orcid.org/0000-0001-6307-964X

\section{AUTHOR CONTRIBUTIONS}

Conceptualization: KS. Data curation: KS, RF. Formal analysis: KS, RF, GS, TA. Methodology: KS, RF, GS, TA. Project administration: KS. Visualization: KS. Writing original draft: KS, RF. Writing - review \& editing: KS, RF, TA.

\section{REFERENCES}

1. Schnitzbauer AA, Lang SA, Goessmann H, Nadalin S, Baumgart J, Farkas SA, et al. Right portal vein ligation combined with in situ splitting induces rapid left lateral liver lobe hypertrophy enabling 2-staged extended right hepatic resection in small-for-size settings. Ann Surg 2012;255:405-414.

2. Schadde E, Ardiles V, Robles-Campos R, Malago M, Machado M, Hernandez-Alejandro R, et al. Early survival and safety of ALPPS: first report of the International ALPPS Registry. Ann Surg 2014;260:829-836; discussion 836-838.

3. Enne M, Schadde E, Björnsson B, Hernandez Alejandro R,
Steinbruck K, Viana E, et al. ALPPS as a salvage procedure after insufficient future liver remnant hypertrophy following portal vein occlusion. HPB (Oxford) 2017;19:1126-1129.

4. de Santibañes M, Alvarez FA, Santos FR, Ardiles V, de Santibañes E. The associating liver partition and portal vein ligation for staged hepatectomy approach using only segments I and IV as future liver remnant. J Am Coll Surg 2014;219:e5-e9.

5. Steinbrück K, D’Oliveira M, Cano R, Enne M. Monosegmental ALPPS after bilateral hepatectomy. Ann Hepatol 2017;16:814-817.

6. Montalvá Orón EM, Maupoey Ibáñez J, Bañuelos Carrillo R, Boscà Robledo A, Orbis Castellanos JF, Moya Herraiz Á, et al. Monosegment ALPPS: a new variant of the techniques for rapid hepatic regeneration. Critical review of the initial results of our series. Cir Esp 2015;93:436-443.

7. Alonso Casado O, Ortega Pérez G, Encinas García S, Saiz Martínez R, González Moreno S. Conversion to segment 4-1 ALPPS associated with right bile duct section and external tube for the control of progression through the bile duct of colorectal metastases. Cir Esp 2017;95:354-357.

8. Pineda-Solís K, Paskar D, Tun-Abraham M, Hernandez-Alejandro R. Expanding the limits of resectability: associating liver partition and portal vein ligation for staged hepatectomy (ALPPS) using monosegment 6 , facilitated by an inferior right hepatic vein. J Surg Oncol 2017;115:959-962.

9. Soggiu F, Giovinazzo F, Straiton J, Turri G, Phillips J, Al-Kari $\mathrm{B}$, et al. Monosegment ALPPS hepatectomy preserving segment 4 for colorectal liver metastases: literature review and our experience. Hepatobiliary Surg Nutr 2018;7:105-115.

10. Ruiz Figueroa EF, Fernández-Placencia RM, Berrospi Espinoza FE, Gomez HF, Chávez Passiuri IK. Monosegmental ALPPS: a long-term survival alternative to liver transplant in PRETEXT IV hepatoblastoma. J Surg Case Rep 2019;2019:rjz144.

11. Schadde E, Malagó M, Hernandez-Alejandro R, Li J, Abdalla E, Ardiles V, et al. Monosegment ALPPS hepatectomy: extending resectability by rapid hypertrophy. Surgery 2015;157:676689.

12. Ha S, Alshahrani AA, Hwang S. ALPPS in a patient with periductal infiltrating intrahepatic cholangiocarcinoma. Ann Hepatobiliary Pancreat Surg 2017;21:223-227.

13. Papamichail M, Pizanias M, Yip V, Prassas E, Prachalias A, Quaglia A, et al. Associating liver partition and portal vein ligation for staged hepatectomy (ALPPS) procedure for hepatocellular carcinoma with chronic liver disease: a case report and review of literature. Korean J Hepatobiliary Pancreat Surg 2016; 20:75-80.

14. Rahbari NN, Garden OJ, Padbury R, Brooke-Smith M, Crawford M, Adam R, et al. Posthepatectomy liver failure: a definition and grading by the International Study Group of Liver Surgery (ISGLS). Surgery 2011;149:713-724. 